\title{
Sistem Informasi Geografis Penyedia Jasa Rumah Kos Berbasis Website (Studi Kasus: Wilayah Kotabumi Lampung Utara)
}

\author{
Ferly Ardhy 1 \\ ${ }^{1}$ Program Studi Sistem Informasi, STMIK DCC Lampung, Indonesia \\ 1ferly@dcc.ac.id
}

\begin{abstract}
Geographic Information System is a special information system that manages data that has spatial information (spatial reference). Or in a narrower sense, is a computer system that has the ability to build, store, manage and display geo-referenced information, such as data identified by its location in a database.

With this rapid technological progress, the author tries to implement one of the GIS application program into the form of Kost Home layout information in Kotabumi. The author tries to build an application that will help to simplify the search such as information about home boarding services, home boarding locations, and strategic location of boarding house. The system to be created is "Geographic Information System Provider of Kost Home Based Website". The development used in this research is the development with Object Oriented model that uses several tools such as Use Case, Activity Diagram, and Class Diagram. And for system development method used is Prototyping development method.
\end{abstract}

Keywords: GIS; Object Oriented; Prototyping.

\begin{abstract}
Abstrak
Sistem Informasi Geografis adalah sistem informasi khusus mengelola data yang memiliki informasi spasial (bereferensi keruangan). Atau dalam arti yang lebih sempit, adalah sistem komputer yang memiliki kemampuan untuk membangun, menyimpan, mengelola dan menampilkan informasi bereferensi geografis, misalnya data yang diidentifikasi menurut lokasinya dalam sebuah database.Dengan kemajuan teknologi yang sangat pesat ini, penulis mencoba mengimplementasikan salah satu program aplikasi SIG kedalam bentuk informasi tata letak Rumah Kost di Kotabumi. Penulis mencoba membangun sebuah aplikasi yang akan membantu untuk mempermudah dalam pencarian seperti informasi tentang jasa rumah kost, lokasi rumah kost, dan letak strategis rumah kost. Sistem yang akan dibuat adalah "Sistem Informasi Geografis Penyedia Jasa Rumah Kost Berbasis Website".Adapun pengembangan yang digunakan dalam penelitian ini adalah pengembangan dengan model Object Oriented yang menggunakan beberapa alat bantu seperti Use Case, Diagram Activity, dan Class Diagram. Dan untuk metode pengembangan sistem yang digunakan adalah metode Prototyping.
\end{abstract}

Kata Kunci : SIG; Object Oriented; Prototyping.

\section{PENDAHULUAN}

Perkembangan teknologi yang sangat pesat saat ini membuat arus kebutuhan dalam dunia teknologi informasi turut berkembang cepat. Internet sebagai salah satu media untuk mendapatkan informasi juga semakin mudah diakses dari mana saja. Dengan berkembangnya teknologi internet, seseorang semakin di mudahkan dalam melakukan segala macam fasilitas dan proses, salah satu contohnya adalah pencarian alamat jasa penyedia rumah kost di kotabumi, dimana terkadang seseorang sulit mencari alamat penyedia rumah kost, khususnya seseorang yang berasal dari luar daerah. Berdasarkan kondisi diatas pada proyek akhir ini dibuat sebuah program untuk memberikan solusi yaitu 
pencarian alamat penyedia rumah kost yang diakses lewat website. Dengan demikian sistem informasi geografis ini akan menampilkan alamat secara visual berdasarkan google map sehingga penyedia jasa rumah kost di kotabumi informasinya akan tersebar melalui sistem.

\section{KERANGKA TEORI}

\subsection{Sistem Informasi Geografis (SIG)}

Sistem Informasi Geografi (SIG) merupakan ilmu pengetahuan yang berbasis pada perangkat lunak komputer yang digunakan untuk memberikan bentuk digital dan analisa terhadap permukaan geografi bumi sehingga membentuk suatu informasi keruangan yang tepat dan akurat (Suryantoro, 2013).

Definisi SIG selalu berubah, hal ini terlihat dengan banyaknya definisi SIG yang telah beredar dan juga SIG merupakan bidang kajian ilmu dan teknologi yang relatif masih baru. Berikut adalah definisi SIG dari beberapa pustaka yang beredar (Suryantoro, 2013):

a) SIG adalah kumpulan yang terorganisir dari perangkat keras komputer, perangkat lunak, data geografi dan personil yang dirancang secara efisien untuk memperoleh, menyimpan, memperbarui, memanipulasi, menganalisis dan menampilkan semua bentuk informasi yang bereferensi geografi.

b) SIG adalah sistem komputer yang digunakan untuk memanipulasi data geografi, sistem ini diimplementasikan dengan perangkat keras komputer dan perangkat lunak komputer yang berfungsi untuk: (a) akusisi dan verifikasi data, (b) kompilasi data, (c) penyimpanan data, (d) perubahan dan updating data, (e) manajemen dan pertukaran data, (f) manipulasi data, (g) pemanggilan dan presentasi data, (h) analisis data.

c) SIG merupakan suatu sistem yang mengorganisir perangkat keras (hardware), perangkat lunak (software), dan data, serta dapat mendayagunakan sistem penyimpanan, pengolahan, maupun analisis data secara stimultan, sehingga dapat diperoleh informasi yang berkaitan dengan aspek keruangan.

Pada sebuah aplikasi SIG, pada umumnya terdapat beberapa fasilitas informasi yang hampir sama dengan sebuah peta, akan tetapi tentunya menyediakan tool yang menyediakan fasilitas untuk memasukkan, menyimpan, memeriksa, mengintegrasikan, memanipulasi, menganalisa, dan menampilkan data (Suryantoro, 2013).

Aplikasi SIG menggunakan dua jenis data untuk merepresentasikan tentang suatu objek, daerah atau fenomena yang terdapat di dunia nyata. Pertama, jenis data yang merepresentasikan aspek-aspek keruangan dari fenomena yang bersangkutan. Jenis data ini sering disebut data posisi, koordinat, ruang atau spasial. Sedangkan yang kedua adalah jenis data yang merepresentasikan aspek-aspek deskriptif dari fenomena yang dimodelkannya. Aspek deskriptif ini mencakup items atau properties dari fenomena yang bersangkutan hingga dimensi waktunya. Jenis data ini sering disebut sebagai data atribut atau data nonspasial (Suryantoro, 2013).

Sistem Informasi Geografi (SIG) atau Geographic Information System (GIS) adalah suatu sistem informasi yang dirancang untuk bekerja dengan data yang bereferensi spasial atau berkoordinat geografi atau dengan kata lain suatu SIG adalah suatu sistem basis data dengan kemampuan khusus untuk menangani data yang bereferensi keruangan (spasial) bersamaan dengan seperangkat operasi kerja (Barus dan Wiradisastra, 2000). Sedangkan menurut Anon (2001) Sistem Informasi geografi adalah suatu sistem Informasi yang dapat memadukan antara data grafis (spasial) dengan data teks (atribut) objek yang dihubungkan secara geogrfis di bumi (georeference). 
Disamping itu, SIG juga dapat menggabungkan data, mengatur data dan melakukan analisis data yang akhirnya akan menghasilkan keluaran yang dapat dijadikan acuan dalam pengambilan keputusan pada masalah yang berhubungan dengan geografi.

Dalam bidang perencanaan wilayah dan kota, ilmu ini memiliki peranan yang sangat penting. Menata ruang suatu wilayah membutuhkan dukungan data dan informasi, baik spasial maupun non spasial, yang akurat dan terkini, terutama data dan informasi tematik yang mengilustrasikan kondisi suatu wilayah. Perubahan kondisi wilayah pada daerah yang akan disusun rencana tata ruangnya, perlu dipahami dengan baik oleh para perencana, karena kualitas rencana tata ruang sangat ditentukan oleh pemahaman para perencana terhadap kondisi fisik wilayah perencanaan. Dengan menggunakan teknologi informasi yang telah berkembang dengan pesat, sebagian data dan informasi spasial yang diperlukan dalam perencanaan tata ruang dapat dibangun dalam sebuah sistem informasi yang berbasis pada koordinat geografis yang lebih dikenal dengan sebutan Sistem Informasi Geografis (SIG)

\subsection{Google Maps API}

Google Maps adalah sebuah jasa peta globe virtual gratis dan online disediakan oleh Google dan dapat ditemukan di http://maps.google.com/. Google Maps menawarkan peta yang dapat diseret dan gambar satelit untuk seluruh dunia dan baru-baru ini, dan juga menawarkan perencana rute dan pencari letak bisnis di U.S., Kanada, Jepang, Hong Kong, Cina, UK, Irlandia (hanya pusat kota) dan beberapa bagian Eropa. Google Maps API merupakan aplikasi interface yang dapat diakses lewat javascript agar Google Maps dapat ditampilkan pada halaman web yang sedang kita bangun. Untuk dapat mengakses Google Maps, Kita harus melakukan pendaftaran API Key terlebih dahulu dengan data pendaftaran berupa nama domain web yang kita bangun.

\subsection{Sistem Model Prototyping}

Prototype atau Prototyping merupakan salah satu metode pengembangan perangkat lunak yang banyak digunakan. Dengan metode prototyping ini pengembang dan pelanggan dapat saling berinteraksi selama proses pembuatan sistem. Sering terjadi seorang pelanggan hanya mendefinisikan secara umum apa yang dikehendakinya tanpa menyebutkan secara detail output apa saja yang dibutuhkan, pemprosesan, dan data-data apa saja yang dibutuhkan. Sebaliknya di sisi pengembang kurang memperhatikan efisiensi algoritma, kemampuan sistem operasi, dan interface yang menghubungkan manusia dan komputer.

Tahapan-tahapan dalam Prototyping adalah sebagai berikut:

a. Planning

Proses memahami mengapa sistem harus dibangun dan mendefinisikan persyaratan. Ini juga mencakup studi kelayakan dari perspektif yang berbeda, teknis, ekonomi, dan aspek kelayakan organisasi.

b. Analysis

Fase ini meliputi kegiatan seperti mengidentifikasi masalah dan analisis, dan bahkan memprediksi potensi masalah yang mungkin timbul di masa depan mengenai sistem. Kiriman / produk dari fase ini akan mendorong bagaimana sistem akan dibangun dan membimbing karya pengembang. 
c. Design

Desain analisis sistem mengarah ke desain keputusan, yang justru menentukan bagaimana sistem beroperasi dalam hal proses, data, perangkat keras, infrastruktur jaringan, antarmuka pengguna, dan faktorfaktor penting lainnya dalam lingkungan sistem.

\section{d. Implementation}

Fase ini yang paling memakan waktu, sumber daya, biaya. ini adalah ketika sistem sebenarnya dibangun, diuji, dan akhirnya diinstal, juga mencakup kegiatan seperti pelatihan pengguna dan pemeliharaan sistem.

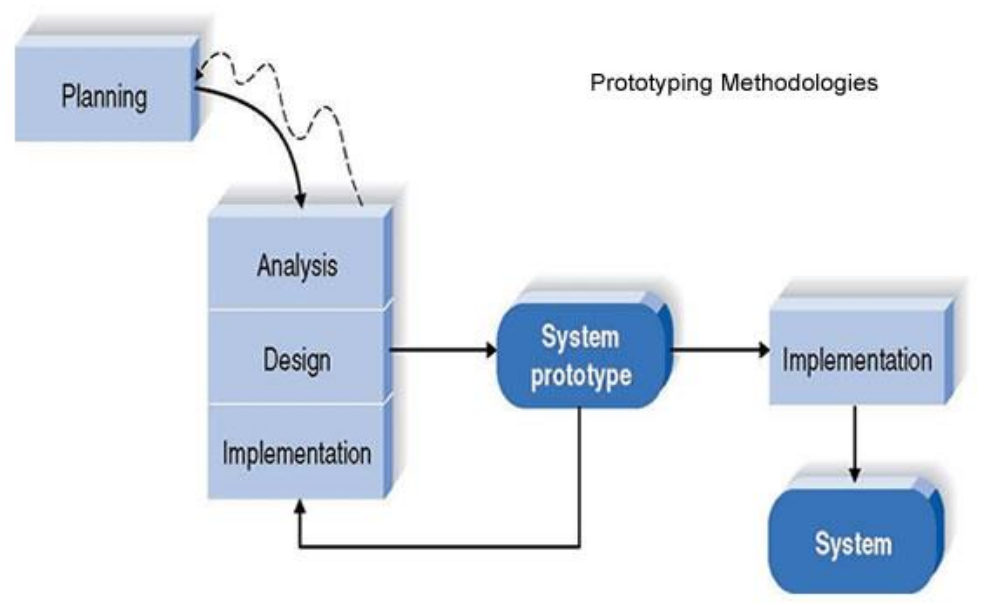

Gambar 1. Metodologi Prototyping

\section{METODOLOGI}

\subsection{Teknik Pengumpulan Data}

Merupakan kegiatan untuk mencari, mendapatkan, serta mengolah data untuk menghasilkan suatu jawaban dari permasalahan yang telah ditentukan. Adapun berbagai teknik pengumpulan data yang dilakukan adalah sebagai berikut:

\section{a. Wawancara}

Wawancara adalah bentuk komunikasi langsung antara peneliti dan responden. Wawancara juga merupakan suatu cara pengumpulan data yang digunakan untuk memperoleh informasi langsung dari sumbernya. Ada beberapa faktor yang akan mempengaruhi arus informasi dalam wawancara, yaitu: pewawancara, responden, pedoman wawancara dan situasi wawancara. Pewawancara adalah petugas pengumpuk informasi yang diharapkan dapat menyampaikan pertanyaan dengan jelas dan merangsang responden untuk menjawab semua pertanyaan dan mencatat semua informasi yang dibutuhkan dengan benar. Responden adalah pemberi informasi yang diharapkan dapat menjawab semua pertanyaan dengan jelas dan lengkap.

Pedoman wawancara berisi tentang uraian penelitian yang biasanya dituangkan dalam bentuk daftar pertanyaan agar proses wawancara dapat berjalan dengan baik. Situasi wawancara ialah berhubungan dengan waktu dan tempat wawancara. Wawancara yang berdasarkan sifat pertanyaan, maka dapat dibagi menjadi tiga, yaitu: wawancara terpimpin, wawancara bebas dan wawancara bebas terpimpin. Dan dari bentuk pertanyaannya dibagi menjadi tiga bentuk lagi, yaitu: wawancara berstruktur, wawancara tak berstruktur dan 
campuran. Pengumpulan data dengan cara melakukan komunikasi dan wawancara secara langsung dengan Pemilik Penyedia Rumah Kost untuk mendapatkan informasi dan data-data yang dibutuhkan

\section{b. Observasi}

Sebagai metode pengumpulan data, observasi dapat diartikan sebagai pengamatan dan pencatatan secara sistematik terhadap unsur yang tampak dalam suatu grjala pada objek penelitian. Unsur yang tampak itu dinamakan dengan data atau informasi yang harus diamati dan dicatat secara benar dan lengkap. Metode ini dipakai untuk mengamati secara langsung keadaan di lapangan agar peneliti mendapatkan gambaran yang lebih luas tentang permasalahan yang diteliti.

Observasi sebagai metode penelitian data mempunyai ciri yang spesifik bila dibandingkan dengan metode yang lainya, yaitu angket dan wawancara. Jika angket dan wawancara berkomunikasi dengan orang, maka observasi tidak hanya pada orang saja melainkan terhadap objek-objek alam yang lain. Metode pengumpulan data dengan observasi digunakan jika penelitian berkenaan dengan perilaku manusia, proses kerja, gejala alam dan jika responden yang diamati tidak terlalu besar.

Pengumpulan data dengan melakukan pengamatan secara langsung pada lokasi Penyedia Rumah Kost dengan mencatat hal-hal penting yang berhubungan dengan penelitian ini, sehingga diperoleh data yang lengkap dan akurat.

\section{c. Studi Pustaka}

Pengumpulan data dengan menggunakan atau mengumpulkan sumber-sumber tertulis, dengan cara membaca, mempelajari, dan mencatat hal-hal penting yang berhubungan dengan masalah yang sedang dibahas guna memperoleh gambaran secara teoritis yang dapat menunjang pada peneitian ini.

\subsection{Metode Pengembangan Sistem}

Metode pengembangan system yang digunanakan pada penelitian kali ini adalah Metode Prototyping. Implementasi Prototyping pada penelitian kali ini meliputi :

\section{a. Planning}

Pada fase ini peneliti terlebih dahulu akan merencanakan dan mengidentifikasikan semua kebutuhan (data), dan garis besar tentang sistem yang akan dibuat. Data disini dapat berupa informasi tentang lokasi kordinat rumah kost, harga perbulan / pertahun, dan data-data lainnya, yang nantinya data tersebut akan ditampilkan pada publik dalam bentuk informasi yang dibutuhkan.

\section{b. Analisis (System Prototype)}

Pada fase ini peneliti menganalisa kebutuhan data khususnya pada proses bisnis yang akan diterapkan pada sistem. Dilakukan proses penilaian, identifikasi dan evaluasi komponen dan hubungan timbal-balik yang terkait dalam pengembangan system: definisi masalah, tujuan, kebutuhan, prioritas dan kendala-kendala system, ditambah identifikasi biaya, keuntungan dan estimasi jadwal untuk solusi yang berpotensi. Fase analisis sistem adalah fase profesional sistem melakukan kegiatan analisis sistem. Laporan yang dihasilkan menyediakan suatu landasan untuk membentuk suatu tim proyek sistem dan memulai fase analisis sistem. 
Tim proyek sistem memperoleh pengertian yang lebih jelas tentang alasan untuk mengembangkan suatu sistem baru.

\section{c. Design (System Prototype)}

Pada fase ini kegiatan yang akan dilakukan merencanakan design prototype seperti yang akan dimplementasikan sesuai dengan analisis permasalahan, analisis kebutuhan dan analisis kelayakan seperti biaya dan manfaat.

\section{d. Implementation (System Prototype)}

Pada fase ini adalah fase pengembangankomponen dan fitur-fitur system yang akan dimplementasikan melalui kode-kode program. laporan implementasi yang dibuat pada fase ini ada dua bagian, yaitu:

1. Rencana implementasi dalam bentuk Gant Chart atau Program and Evaluation Review Technique (PERT) Chart

2. Penjadwalan proyek dan teknik manajemen. Bagian kedua adalah laporan yang menerangkan tugas penting untuk melaksanakan implementasi sistem, seperti : Pengembangan perangkat lunak, Persiapan lokasi peletakkan system, Instalasi peralatan yang digunakan, Pengujian Sistem

\section{HASIL DAN PEMBAHASAN}

\subsection{Analisis Sistem (System Prototype)}

Analisis sistem metode untuk menemukan kelemahan dan kebutuhan sistem yang bertujuan untuk memperoleh gamabaran sistem yang akan diterapkan melalui identifikasi user terhadap implementasi perangkat lunak. Berikut adalah hasil analisis yang telah dilakukan :

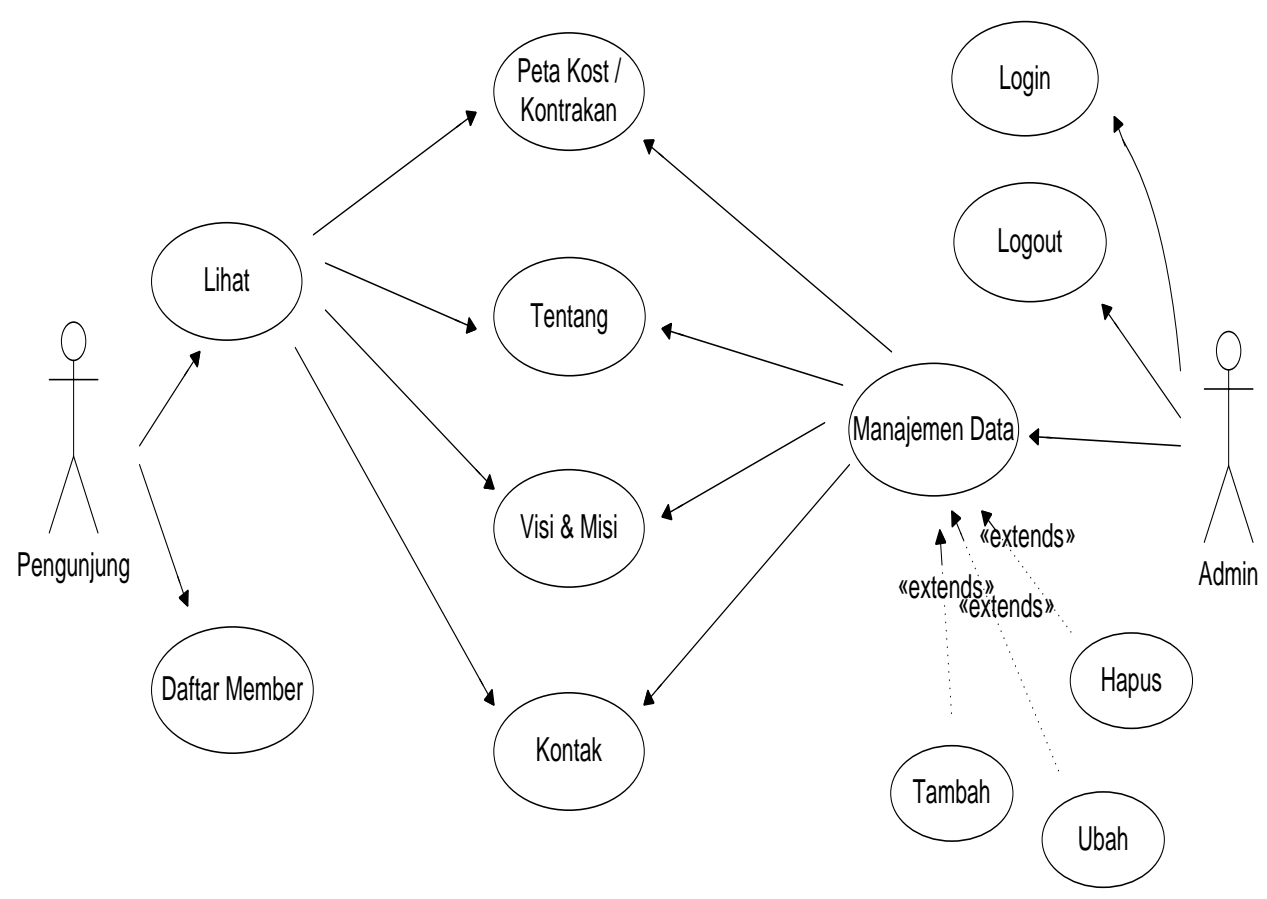

Gambar 2 Usecase Pengunjung 


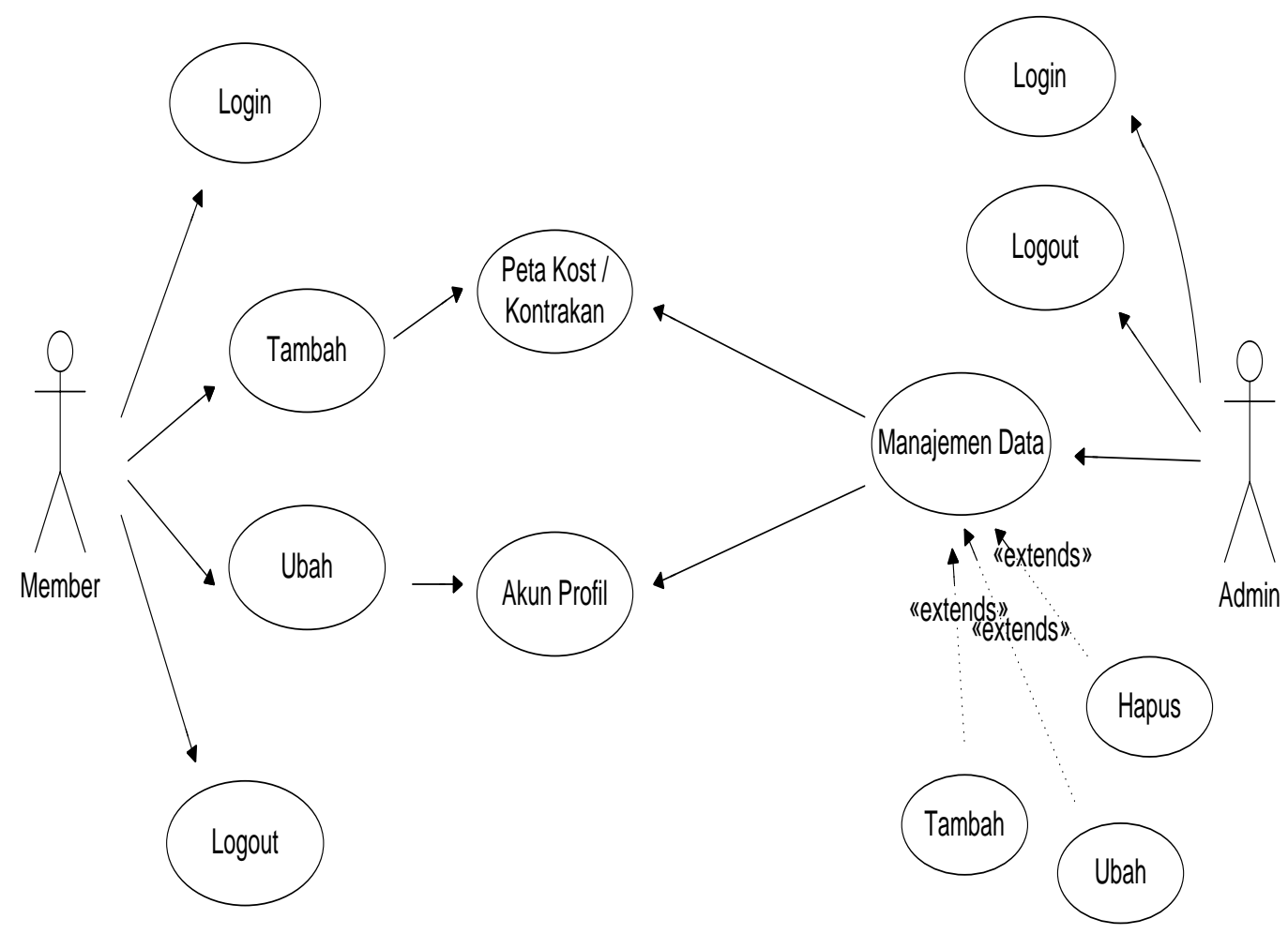

Gambar 3 Usecase Member

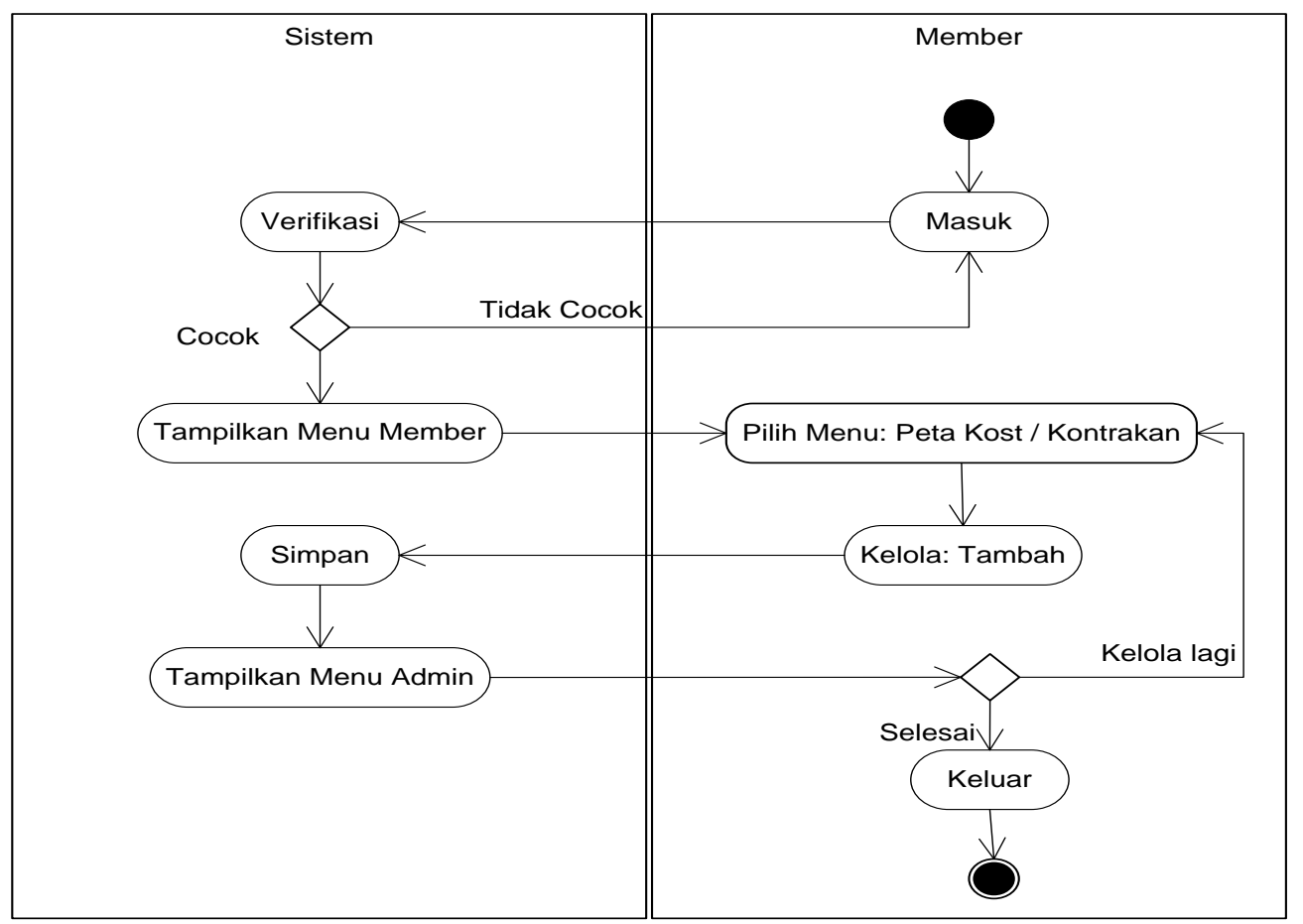

Gambar 4 Activity Diagram Sistem Pencarian

\subsection{Design (System Prototype)}

Penulis mengusulkan rancangan system berbasis website untuk mengelola informasi geografis untuk mengelola jasa penyedia rumah kost sehingga bisa diakses oleh banyak user melalui teknologi internet. Berikut rancangan class diagram yang akan diimplementasikan 


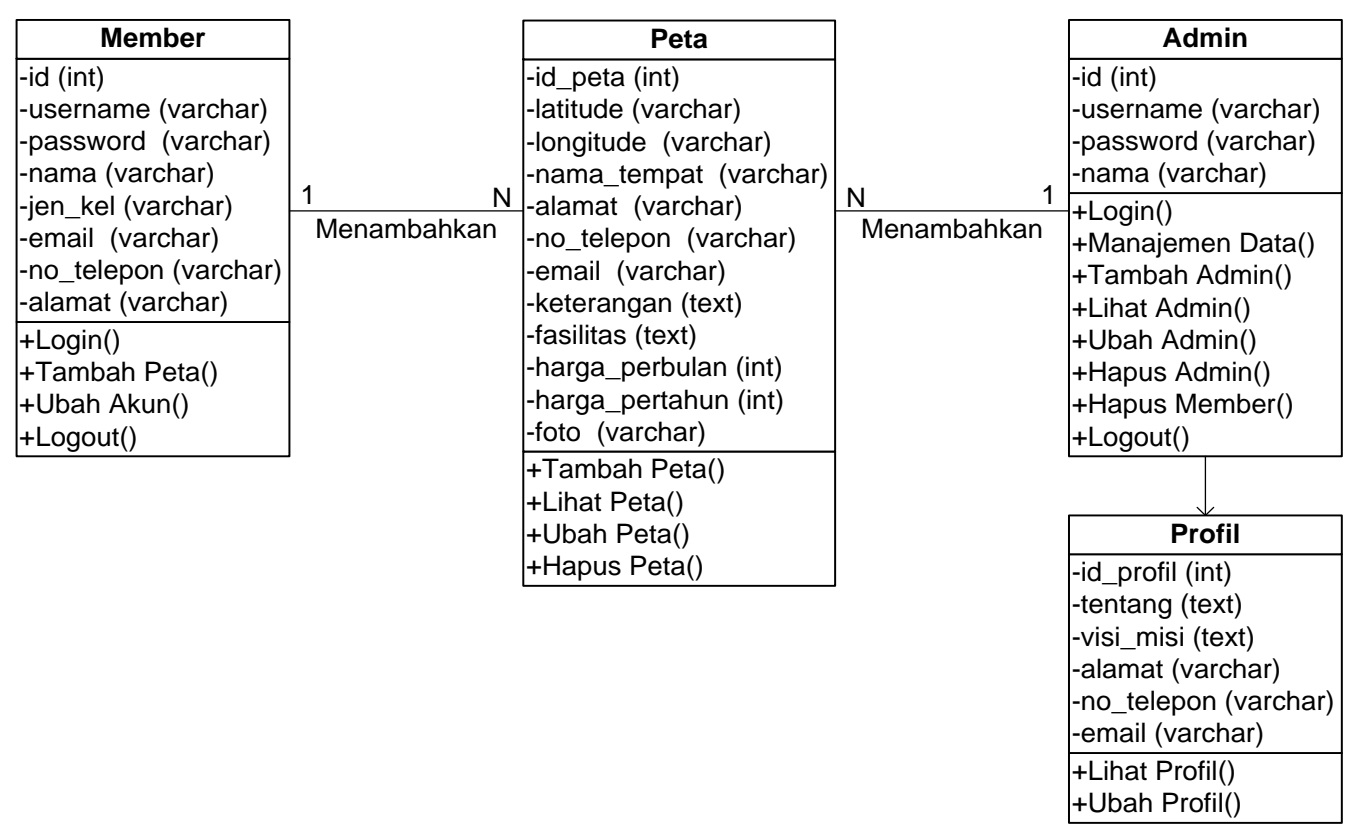

Gambar 5 Class Diagram Sistem

\subsection{Implementasi Dan Pembahasan}

Tahap implementasi merupakan tahap lanjutan dari fase perancangan. Pada fase ini hasil rancangan sebelumnya akan diimplementasikan ke dalam bahasa pemrograman sehingga akan menghasilkan sebuah aplikasi yang dibutuhkan. Aplikasi yang dihasilkan berupa Sistem Informasi Geografis tentang pencarian jasa rumah kost yang akan berjalan di platform windows sehingga bisa diakses oleh banyak user.

\subsubsection{Halaman Admin}

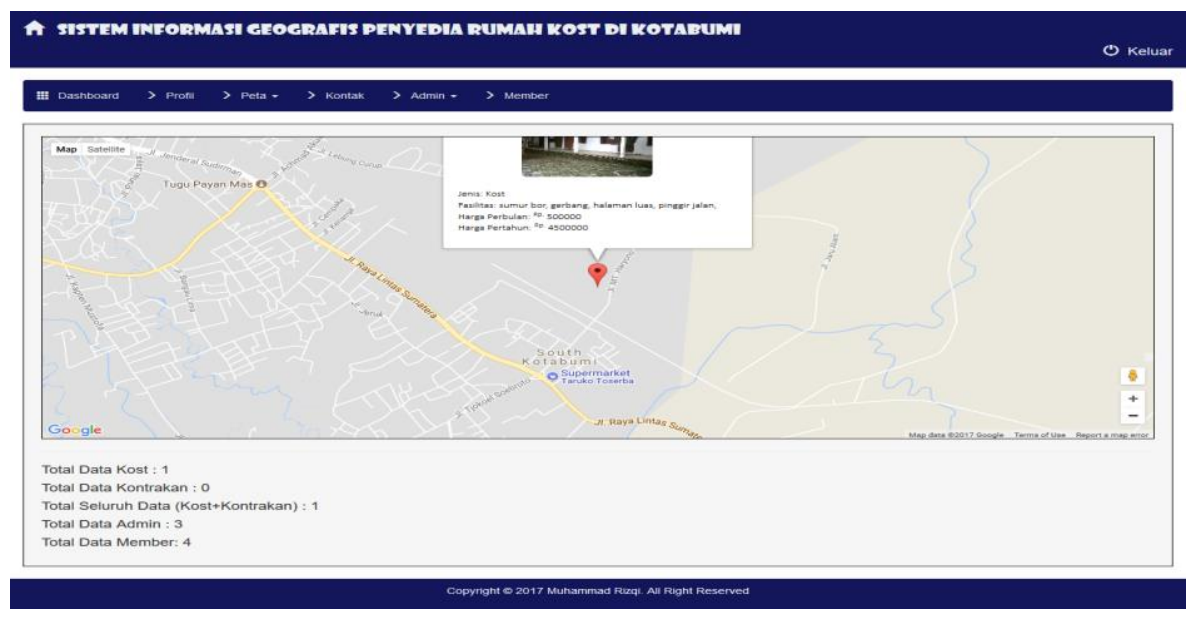

Gambar 6 Halaman Menu Utama

Menu home dari Sistem Informasi Geografis ini. Di halaman ini Pengunjung dapat memilih menu-menu yang tersedia seperti profil web, contact admin, peta kost, dan lain-lain untuk mendapatkan informasi yang dibutuhkan oleh pengunjung. 


\subsubsection{Halaman Menu Member}

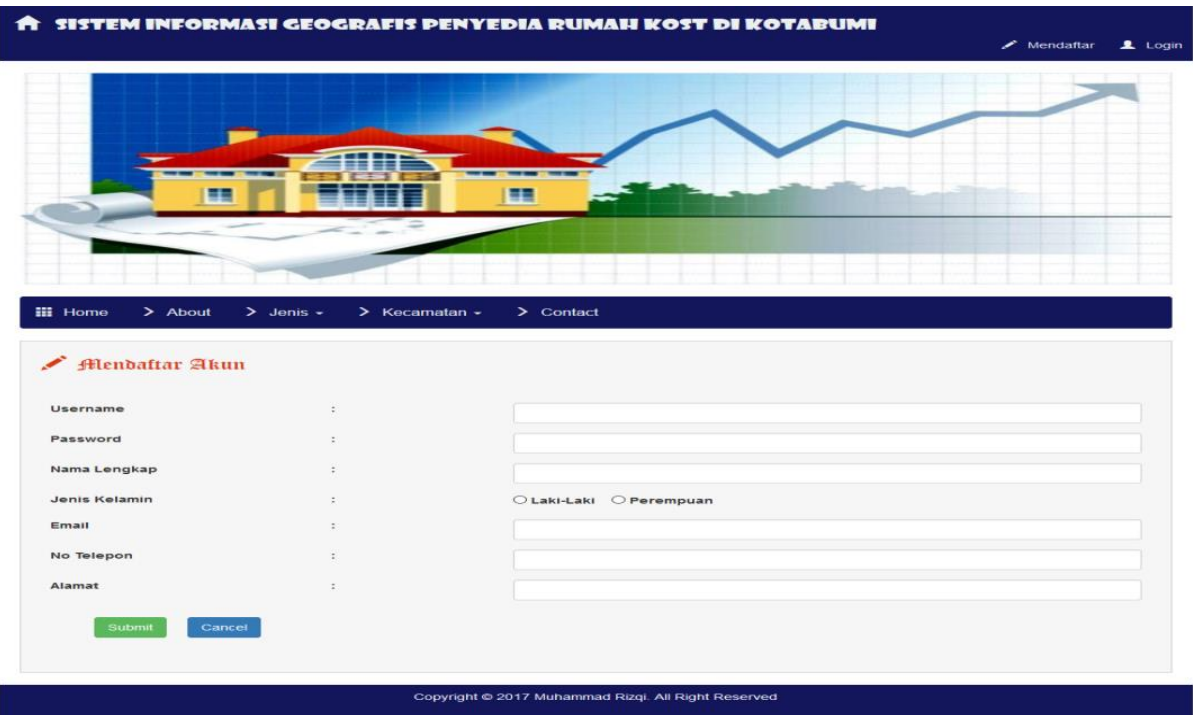

\section{Gambar 7 Halaman Menu Member}

Pada halaman ini berfungsi jika ada pengunjung yang akan melakukan pencarian rumah kost, maka pengujung tersebut harus melakukan pendaftaran sebagai member.

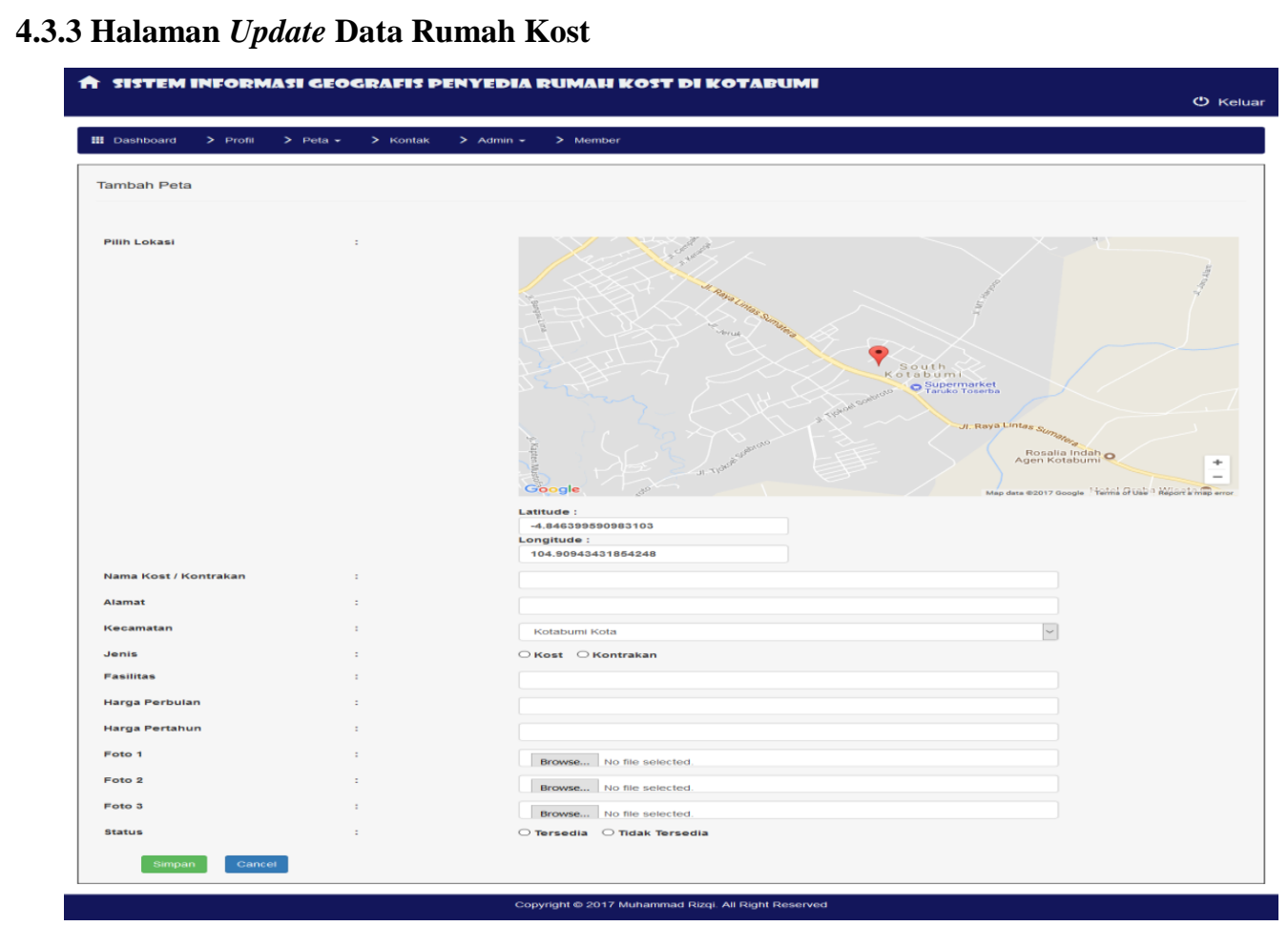

Gambar 8 Halaman Update Data Rumah Kost

Pada halaman ini admin dapat memposting atau menambahkan peta rumah kost. Data tersebut nanti akan ditampilkan pada halaman publik. 


\section{KESIMPULAN}

Dari hasil perancangan dan implemetasi dapat disimpulkan sebagai berikut:

a. Website Sistem Informasi Geografis tentang jasa rumah kost di Kotabumi telah berhasil dibangun.

b. Sistem Informasi Geografis Rumah Kost ini sangat membantu para pencari jasa rumah kost untuk mengetahui tentang lokasi rumah kost serta informasi tentang jasa rumah kost.

c. Dengan adanya Website ini juga dapat membantu bagi pemilik penyedia jasa rumah kost dalam memasarkan jasa rumah kost yang dimilikinya.

\section{DAFTAR PUSTAKA}

Andry Rachmadi. 2013 Sistem Informasi Rumah Kost Berbasis Web di Yogyakarta. Yogyakarta. Universitas Islam

Ardiansyah. 2014. Penerapan Google Maps Api dalam pembuatan sistem informasi geografis rumah kos berbasis web yogyakarta. Yogyakarta. Sekolah Manajemen Informatika dan Komputer Amikom.

Fitri Damayanti, Holil. Juni 2016 diakses pada tanggal 15 juli 2017. Sistem Informasi Rumah Kost Berbasis Web Dan Google Maps Api, Jurnal Ilmiah Multitek Indonesia, Vol. 10, No.1, ISSN : 1907-6223

Wimagguc, Google Maps Latitude and Longitude Picker. 27 juni 2013. diakses pada tanggal 15 juli 2017. http://www.wimagguc.com/2013/06/jquery latitude-and-longitude-picker-gmaps/. 